\title{
Nationwide high prevalence of CTX-M and an increase of CTX-M-55 in Escherichia coli isolated from patients with community-onset infections in Chinese county hospitals
}

\author{
Jing Zhang, Beiwen Zheng, Lina Zhao, Zeqing Wei, Jinru Ji, Lanjuan Li and Yonghong Xiao*
}

\begin{abstract}
Background: In order to investigate the epidemiology, molecular characteristics, and distribution of extended-spectrum $\beta$-lactamase (ESBL)- and AmpC-producing Escherichia coli from community-onset infections in Chinese county hospitals.

Methods: E. coli isolates were collected from patients with community-onset infections in 30 county hospitals. ESBL activity was confirmed by double-disc diffusion. Genetic confirmation and molecular typing of ESBL- and AmpC-producing isolates was determined by PCR and DNA sequencing. ESBL-positive isolates were further characterised by multi-locus sequence typing.

Results: Of 550 E. coli isolates, 256 (46.5\%) carried ESBL genes and all were of the CTX-M type. The prevalence of ESBL-producing strains varied from $30.2 \%$ to $57.0 \%$ across different regions of China. Overall, 12 bla were detected; the most abundant were bla $a_{\mathrm{CTX}-\mathrm{M}-14}(163 / 256$ isolates, $64.5 \%), \mathrm{bla}_{\mathrm{CTX}-\mathrm{M}-55}(47 / 256,18.4 \%)$, and bla $a_{\text {CTX-M-15 }}$ (31/256, 12.1\%). CMY-2-like AmpC $\beta$-lactamases were detected in 11 strains, three of which co-existed with bla $a_{\text {CTX-M. }}$. A total of 64 sequence types (STs) were detected in 256 ESBL-producing strains, including nine that were new. ST131 was the most abundant type (27 isolates, 12.7\%), followed by ST69 (14 isolates, 6.6\%), ST405 (14 isolates, 6.6\%), and ST38 (12 isolates, 5.6\%).

Conclusions: This study revealed that the widespread prevalence of ESBLS among outpatient infections has reached a high level in county hospitals. The CTX-M genotype was most dominant, comprising a variety of subtypes. This is the first time the incidence of CTX-M- 55 has exceeded that of CTX-M-15 in China. No predominant ST was detected, suggesting that ESBL-producing $E$. coli strains originate in different clones.
\end{abstract}

\section{Background}

The production of extended-spectrum $\beta$-lactamases (ESBLs) is the main mechanism of resistance to $\beta$-lactam antibiotics in E. coli. ESBLs hydrolyse penicillins, cephalosporins, and aztreonam; however, they are inhibited by clavulanic acid, sulbactam, and tazobactam [1,2]. The enzymes TEM and SHV were previously recognised as the main ESBLs. However, CTX-Ms have recently become more prominent, and are now considered to be the most prevalent $\beta$-lactamases found in clinical isolates of $E$. coli globally

\footnotetext{
* Correspondence: xiao-yonghong@163.com

Collaborative Innovation Center for Diagnosis and Treatment of Infectious Diseases, State Key Laboratory for Diagnosis and Treatment of Infectious Disease, The First Affiliated Hospital, College of Medicine, Zhejiang University, Hangzhou 310003, China
}

(C) 2014 Zhang et al.; licensee BioMed Central Ltd. This is an Open Access article distributed under the terms of the Creative Commons Attribution License (http://creativecommons.org/licenses/by/4.0), which permits unrestricted use, distribution, and reproduction in any medium, provided the original work is properly credited. The Creative Commons Public Domain Dedication waiver (http://creativecommons.org/publicdomain/zero/1.0/) applies to the data made available in this article, unless otherwise stated.

[3,4]. A nationwide survey of the United States during 2009-2010 revealed that 91\% of ESBL-producing E. coli strains carried CTX-M-type genes [5]. CTX-M-type ESBLs are also dominant in European and Asian countries $[4,6]$, and in China they are the most common ESBLs found in Gram-negative bacteria isolated from tertiary hospitals [7-9]. ESBL-producing E. coli strains are a major cause of community-associated infections [5,10], and their spread has been well-documented in Europe and North America [5,11-15]. Strains of ESBL-producing E. coli have been recorded in other regions of the world, including Oceania, Asia, and South America [10,16-18]. Several studies have characterised ESBL-producing Enterobacteriaceae in Chinese tertiary hospitals $[7,19,20]$. A national monitoring program of antimicrobial resistance in E. coli 
caused bacteriaemia (mostly nosocomial infections) in Chinese tertiary hospitals reported an increase in ESBLproducing $E$. coli from less than $20 \%$ to $72.2 \%$ between 2000 and 2011 [21-23]. Another survey of Chinese tertiary hospitals reported that the incidence of ESBLproducing $E$. coli among community-associated intraabdominal infections increased from 19.1\% in 2002-2003 to $61.6 \%$ in $2010-2011$ [20]. None of these studies focused on bacteria isolated from outpatients in primary and noncentral city hospitals. In light of the increasing importance of ESBL-producing E. coli within communities, it is important to understand the pattern of antibiotic resistance and the prevalence of ESBLs in bacterial isolates from primary and non-central city healthcare institutions that provide medical services to patients in China.

Most Chinese people live in rural areas or small to medium-sized cities, and seek their healthcare at countylevel hospitals, which play an important role in China. The high global prevalence of ESBL-producing $E$. coli strains among community-onset infections warrants an urgent need to investigate the characteristics of antimicrobial resistance in China. This study focuses on community-onset infections in patients at selected hospitals in seven regions of China. The purpose was to investigate the antimicrobial resistance, the incidence of ESBLs and their genetic types, and the molecular characteristics of $E$. coli strains isolated from patients, with the intention of developing strategies to control and prevent antimicrobial resistance.

\section{Methods}

\section{Collection of clinical isolates}

Thirty county hospitals were selected for this investigation (see Additional file 1), which took place between August 2010 and August 2011, and in total 550 E.coli were collected. These hospitals are located in 11 different provinces and represent seven geographic regions of China. In China, hospitals are categorized by the level of service provision, size, medical technology, medical equipment, and management and medical quality into 3 subsidiary levels, primary hospitals, secondary hospitals, tertiary hospitals. All the county hospitals included in this study are secondary hospitals. Patients were selected for this study using the following criteria: 1) they attended an outpatient clinic or emergency department and were diagnosed with a bacterial infection less than 48 hours after they were hospitalised; 2) they were not admitted to hospital within 90 days prior to diagnosis; 3) they did not have long-term indwelling catheters; and 4) and they had not received antibacterial therapy or had received less than 72 hours of antibacterial therapy prior to seeing a doctor. Bacterial strains were isolated from clinical specimens (urine, blood, sputum, abscesses, and secretions) and identified using API20 (bioMérieux, Durham, NC, USA). Samples were collected as part of routine care from outpatients; pathogens were isolated by standard microbiological methods by the microbiologists of the participant county hospitals. All the pure cultures were frozen at $-80^{\circ} \mathrm{C}$ and shipped to our laboratory for definite identification and further analysis. The identities of all isolates were ratified using Matrix-assisted laser desorption ionisation-time of flight mass spectrometry (MALDI-TOF) as described previously [24].

\section{Antimicrobial susceptibility testing}

Antimicrobial susceptibility was tested using the standard agar dilution method recommended by the Clinical and Laboratory Standards Institute guidelines (M100-S21) [25]. The breakpoint of biapenem was based on the recommended point of imipenem by CLSI. The following antimicrobial agents were tested: ampicillin, piperacillin, cefazolin, cefuroxime, ceftazidime, ceftriaxone, cefepime, ampicillin-sulbactam, piperacillin-tazobactam, cefoxitin, biapenem, imipenem, meropenem, amikacin, gentamicin, ciprofloxacin, levofloxacin, and fosfomycin (Chinese National Institute for the Control of Pharmaceutical and Biological Products). ESBL activity was determined by the double-disc diffusion method using ceftazidime (30 $\mu \mathrm{g})$, ceftazidime plus clavulanate $(30 / 10 \mu \mathrm{g})$ discs and cefotaxime $(30 \mu \mathrm{g})$, and cefotaxime plus clavulanic acid $(30 / 10 \mu \mathrm{g})$ discs (Oxoid Limited, UK) on Mueller-Hinton agar (Oxoid Limited, UK) [25]. The results of antimicrobial susceptibility testing were analyzed by WHONET5.6. The reference strains used for this study were E. coli ATCC 25922 and Klebsiella pneumoniae ATCC 700603.

\section{Detection of $\beta$-lactamase genes}

PCR amplification was used to detect $b l a_{\mathrm{CTX}-\mathrm{M}}, b l a_{\mathrm{SHV}}$, bla $a_{\mathrm{TEM}}, b l a_{\mathrm{OXA}}, b l a_{\mathrm{VEB}}, b l a_{\mathrm{PER}}$, and $b l a_{\mathrm{GES}}, b l a_{\mathrm{KPC}}$ and the AmpC $\beta$-lactamase genes bla $a_{\mathrm{CMY}-1}, b l a_{\mathrm{CMY}-2}$, and $b l a_{\mathrm{DHA}} \cdot b l a_{\mathrm{CTX}-\mathrm{M}}$ group-specific primers for CTX-M-1, CTX-M-2, CTX-M-8 and CTX-M-9 groups were used to detect of bla $a_{\mathrm{CTX}-\mathrm{M}}$ genes, and three pair of group specific primers (OXA-1, OXA-2, OXA-10) for detecting $b l a_{\text {OXA }}$. Genomic DNA of clinical isolates was prepared using a modified boiling method [26] and this DNA was used as the template for PCR amplification. PCR products were separated by electrophoresis using a 1\% agarose gel to identify the amplified DNA fragments. Forward and reverse sequencing reactions were performed on an $\mathrm{ABI}$ 3730 automated sequencer using ABI Prism BigDye Terminator version 3.1 cycle sequencing (Applied Biosystems, Foster City, CA, USA). Primers used for PCR detection and sequencing are listed in Table 1 . Gene sequences were analysed online using BLAST (http://blast.ncbi.nlm.nih. gov/Blast.cgi) and identified using a $\beta$-lactamase database (http://www.lahey.org/Studies/). 
Table 1 Primers used for PCR amplification of bla genes

\begin{tabular}{|c|c|c|c|c|}
\hline PCR target & Primer & Sequence $\left(5^{\prime}-3^{\prime}\right)$ & Fragment size, bp & Ref \\
\hline \multirow{2}{*}{ bla TEM } & TEM-F & CATTTCCGTGTCGCCCTTATTC & \multirow{2}{*}{800} & \multirow{2}{*}[27]{} \\
\hline & TEM-R & CGTTCATCCATAGTTGCCTGAC & & \\
\hline \multirow{2}{*}{ bla $a_{\mathrm{SHV}}$} & $\mathrm{SHV}-\mathrm{F}$ & GGTTATGCGTTATATTCGCC & \multirow{2}{*}{867} & \multirow{2}{*}[28]{} \\
\hline & SHV-R & TTAGCGTTGCCAGTGCTC & & \\
\hline \multirow{2}{*}{ CTX-M-1 group } & CTX-M-1F & CCCATGGTTAAAAAATCACTGC & \multirow{2}{*}{942} & \multirow{2}{*}[7]{} \\
\hline & CTX-M-1R & CAGCGCTTTTGCCGTCTAAG & & \\
\hline \multirow{2}{*}{ CTX-M-2 group } & CTX-M-2F & CGACGCTAC CCCTGC TAT T & \multirow{2}{*}{552} & \multirow{2}{*}[29]{} \\
\hline & CTX-M-2R & CCAGCGTCAGATTITTCAGG & & \\
\hline \multirow{2}{*}{ CTX-M-8 group } & CTX-M-8F & AACR(A)CR(G)CAGACGCTCTAC & \multirow{2}{*}{326} & \multirow{2}{*}[27]{} \\
\hline & CTX-M-8R & TCGAGCCGGAAGGTGTCAT & & \\
\hline \multirow{2}{*}{ CTX-M-9 group } & CTX-M-9F & ATGGTGACAAAGAGAGTGCAAC & \multirow{2}{*}{876} & \multirow{2}{*}{ This study } \\
\hline & CTX-M-9R & TTACAGCCCTTCGGCGATGATT & & \\
\hline \multirow{2}{*}{ bla OXA-1 } & OXA-1F & GGCACCAGATTCAACTTTCAAG & \multirow{2}{*}{814} & \multirow{2}{*}[27]{} \\
\hline & OXA-1R & GACCCCAAGTTTCCTGTAAGTG & & \\
\hline \multirow{2}{*}{ bla OXA-2 } & OXA-2F & GGCACCAGATTCAACTTTCAAG & \multirow{2}{*}{702} & \multirow{2}{*}[27]{} \\
\hline & OXA-2R & GATTTGCTCCGTGGCCGAAA & & \\
\hline \multirow{2}{*}{$b l a_{\mathrm{OXA}-10}$} & OXA-10F & ACGGCATTAGCTGGTTCAAT & \multirow{2}{*}{720} & \multirow{2}{*}{ This study } \\
\hline & OXA-10R & TGATITTGGTGGGAATGGAT & & \\
\hline \multirow{2}{*}{$b / a_{\mathrm{GES}}$} & GES-F & AGTCGGCTAGACCGGAAAG & \multirow{2}{*}{399} & \multirow{2}{*}[27]{} \\
\hline & GES-R & TITGTCCGTGCTCAGGAT & & \\
\hline & PER-F & GCTCCGATAATGAAAGCGT & 520 & \\
\hline UIUPER & PER-R & TTCGGCTTGACTCGGCTGA & 520 & {$[21]$} \\
\hline & VEB-F & CATTTCCCGATGCAAAGCGT & 618 & [27] \\
\hline 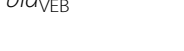 & VEB-R & CGAAGTTTCTTTGGACTCTG & 040 & {$[27]$} \\
\hline & CMY2-F & AACACACTGATTGCGTCTGA & 122 & [30] \\
\hline UIU CMY2 & CMY2-R & TCCTGGGCCTCATCGTCAGTTAT & $12<0$ & [OU] \\
\hline bla & CMY1-F & TATTAGAGCGGTTTAGGCTG & 145 & [30] \\
\hline TIC CMYT & CMY1-R & AATGTACCGCCCTCTITC & 1950 & {$[0]$} \\
\hline blo & DHA-F & TGATGGCACAGCAGGATATTC & 097 & {$[27]$} \\
\hline OIG DHA & DHA-R & GCTITGACTCTITCGGTATTCG & 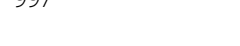 & {$[2 /]$} \\
\hline & KPC-F & CATTCAAGGGCTITCTTGCTGC & 5 & {$[27]$} \\
\hline OMARPC & $K P C-R$ & ACGACGGCATAGTCATTTGC & 538 & {$[2 /]$} \\
\hline
\end{tabular}

\section{Molecular typing of E. coli}

To determine if ESBL genes were disseminated by clonal spread or horizontal gene transfer, isolates $(n=213)$ representing different regions were analysed by multi-locus sequence typing (MLST) following the guidelines found at http://mlst.warwick.ac.uk/mlst/dbs/Ecoli. Sequence typing of the housekeeping genes $a d k$, fum $C, \operatorname{gyr} B, i c d, m d h, p u r A$, and $\operatorname{rec} A$ was performed on all ESBL-producing $E$. coli isolates according to Wirth et al. [31]. Sequence types (STs) were confirmed by comparison with those in the database. A phylogenetic tree of STs detected in this study was constructed using Phylodendron (http://iubio.bio.indiana.edu/ soft/molbio/java/apps/trees/). This tool uses the PHYLIP (a free package of programs for inferring phylogenies) suite of programs to generate trees from allelic profile data.

\section{Statistical analysis}

Statistical significance was determined by $\chi^{2}$ analysis, and Fisher's exact test was used for small sample sizes. Analyses were performed using SPSS version 20.0 (IBM Corporation), and a $p$-value $<0.05$ was considered to be statistically significant.

\section{Ethical approval}

The Ethics committee of The First Affiliated Hospital, College of Medicine, Zhejiang University waived the need 
for formal ethical approval. No institutional review board approval was necessary, because all the personal information of the patients (such as name, height, weight, etc) was not collected during the investigation and the investigation did not have any impact on the patient management. All patients were informed verbally of our study's purpose before sending their pathogens to our laboratory for research.

\section{Results}

\section{Patient demographics and specimen types}

A total of 550 isolates were collected and confirmed as E. coli by MALDI-TOF. The majority of the isolates were recovered from urine specimens (68.5\%), with $8.2 \%$ from blood samples, $7.0 \%$ from sputum samples, $6.8 \%$ from abscesses, 6.0\% from secretions (ascites, pleural fluid), and $3.5 \%$ from other specimens. Females provided $65 \%$ of the isolates. The ages of patients were as follows: $\leq 17$ years, $6.1 \%$; $18-45$ years, $39.2 \%$; $46-64$ years, $38.3 \%$; and $\geq 65$ years, $16.4 \%$.

\section{Antimicrobial susceptibility profiles}

The results of antimicrobial susceptibility tests for all isolates and ESBL-producing strains are summarised in Table 2. All isolates were susceptible to biapenem, imipenem, and meropenem, whereas $94.1 \%, 93.6 \%$, and $91.0 \%$ of strains were susceptible to fosfomycin, amikacin, and piperacillin-tazobactam, respectively. In total, 249 strains produced ESBLs: $100 \%$ of these were resistant to ampicillin, with high resistance also to cefazolin $(99.6 \%, \mathrm{n}=248)$, ceftriaxone $(98.8 \%, \mathrm{n}=246)$, ampicillin-sulbactam $(61.3 \%$, $\mathrm{n}=153)$, ciprofloxacin $(73.5 \%, \mathrm{n}=183)$, and levofloxacin $(68.8 \%, \mathrm{n}=171)$.

\section{Genotypic characterisation and geographical distribution of ESBL- and AmpC-producing isolates}

PCR was performed on all 550 isolates to determine the presence of ESBL and AmpC. These results and the geographic distributions of the isolates are shown in Table 3. The findings revealed that 256 isolates (46.5\%) carried ESBL genes, all of which were the CTX-M type: the CTX-M-9 group (180 isolates) was most abundant, followed by the CTX-M-1 group (91 isolates). The CTXM-2 and CTX-M-8 groups were not detected. Overall, 12 $b l a_{\mathrm{CTX}-\mathrm{M}}$ subtypes were detected: these were $b l a_{\mathrm{CTX} \text {-M-14 }}$ (164 isolates, 65\%, including 17 strains co-existed with other $b l a_{\mathrm{ESBL}}$ or $a m p C$ genes), which is now the most common ESBL in China, bla ${ }_{\mathrm{CTX}-\mathrm{M}-55}$ (47 isolates, $17.7 \%$, including 6 strains co-existed with $\left.b l a_{\mathrm{CTX}-\mathrm{M}-14}\right), b l a_{\mathrm{CTX}-\mathrm{M}-}$ ${ }_{15}$ (30 isolates, $11.7 \%$, including 7 strains co-existed with $b l a_{\mathrm{CTX}-\mathrm{M}-14}$ or $b l a_{\mathrm{CMY}-2}$ genes), $b l a_{\mathrm{CTX}-\mathrm{M}-3}$ (9 isolates, $3.5 \%$, including 3 strains co-existed with other $b l a_{\mathrm{ESBL}}$ or ampC genes), $b l a_{\mathrm{CTX}-\mathrm{M}-24}$ (9 isolates, $3.5 \%$, including 2 strains co-existed with other $b l a_{\mathrm{ESBL}}$ or $\operatorname{ampC}$ genes),

Table 2 Results for susceptibility tests and MICs for $E$. coli strains $(n=550)$ isolated from 30 county hospitals

\begin{tabular}{|c|c|c|c|c|c|c|c|c|}
\hline \multirow[b]{2}{*}{ Antibiotic } & \multicolumn{4}{|c|}{ All isolates $(n=550)$} & \multicolumn{4}{|c|}{ ESBL-positive (phenotype) isolates $(n=249)$} \\
\hline & MIC50 (mg/L) & MIC90 (mg/L) & Susceptible $\%$ & Resistant \% & MIC50 (mg/L) & MIC90 (mg/L) & Susceptible \% & Resistant \% \\
\hline Ampicillin & 256 & $>256$ & 13.6 & 85.1 & $>256$ & $>256$ & 0 & 100 \\
\hline Piperacillin & 64 & $>256$ & 31.8 & 49.5 & 256 & $>256$ & 0 & 91 \\
\hline Ampicillin-Sulbactam & 16 & 64 & 35 & 39.1 & 32 & 64 & 14.7 & 61.5 \\
\hline $\begin{array}{l}\text { Piperacillin- } \\
\text { tazobactam }\end{array}$ & 8 & 16 & 91 & 2.1 & 8 & 32 & 86.5 & 4.5 \\
\hline Cefazolin & 32 & 256 & 46.7 & 51.1 & 256 & 256 & 0.4 & 99.6 \\
\hline Cefuroxime & 8 & 256 & 50.1 & 47.8 & 256 & 256 & 0 & 98.5 \\
\hline Ceftazidime & 0.5 & 32 & 80.4 & 18.3 & 4 & 64 & 55.6 & 40.6 \\
\hline Ceftriaxone & 0.25 & 128 & 55.4 & 44.2 & 64 & 128 & 0.7 & 98.5 \\
\hline Cefepime & 1 & 32 & 77.7 & 13.5 & 8 & 64 & 54.5 & 28.9 \\
\hline Cefoxitin & 4 & 32 & 76.9 & 15 & 8 & 128 & 61.8 & 24.7 \\
\hline Biapenem & 0.064 & 0.125 & 100 & 0 & 0.064 & 0.125 & 100 & 0 \\
\hline Imipenem & 0.125 & 0.25 & 100 & 0 & 0.125 & 0.25 & 100 & 0 \\
\hline Meropenem & 0.064 & 0.125 & 100 & 0 & 0.064 & 0.125 & 100 & 0 \\
\hline Amikacin & 2 & 8 & 93.6 & 6.1 & 2 & 64 & 89.1 & 10.2 \\
\hline Gentamicin & 16 & 128 & 47.2 & 51.5 & 64 & 256 & 33.5 & 66.2 \\
\hline Ciprofloxacin & 4 & 64 & 46.7 & 51 & 32 & 128 & 24.8 & 73.3 \\
\hline Levofloxacin & 4 & 32 & 49.1 & 46.7 & 16 & 64 & 26.2 & 68.9 \\
\hline Fosfomycin & 1 & 32 & 94.1 & 5.1 & 1 & 128 & 88.6 & 9.8 \\
\hline
\end{tabular}


Table 3 Geographical distribution of ESBL- and AmpC-producing E. coli isolates in seven regions of China

\begin{tabular}{|c|c|c|c|c|c|c|c|c|}
\hline \multirow[t]{2}{*}{ ESBL genotype } & \multicolumn{8}{|c|}{ No. of isolates (prevalence, \%) } \\
\hline & $\begin{array}{l}\text { North China } \\
(n=93)\end{array}$ & $\begin{array}{l}\text { Northwest China } \\
(n=81)\end{array}$ & $\begin{array}{l}\text { Northeast China } \\
(n=37)\end{array}$ & $\begin{array}{l}\text { East China } \\
(n=43)\end{array}$ & $\begin{array}{l}\text { South China } \\
(n=109)\end{array}$ & $\begin{array}{l}\text { Central China } \\
(n=109)\end{array}$ & $\begin{array}{l}\text { Southwest } \\
\text { China }(n=78)\end{array}$ & $\begin{array}{l}\text { Total } \\
(n=550)\end{array}$ \\
\hline CTX-M-1 group & 16 & 14 & 7 & 10 & 14 & 10 & 2 & 73 \\
\hline CTX-M-15 & 7 & 6 & 1 & 2 & 3 & 4 & & 23 \\
\hline CTX-M-55 & 6 & 6 & 5 & 7 & 10 & 5 & 2 & 41 \\
\hline CTX-M-3 & 3 & 1 & & 1 & & 1 & & 6 \\
\hline CTX-M-101 & & 1 & & & & & & 1 \\
\hline CTX-M-12 & & & 1 & & & & & 1 \\
\hline CTX-M-1 & 1 & & & & & & & 1 \\
\hline CTX-M-9 group & 32 & 22 & 5 & 3 & 23 & 40 & 36 & 161 \\
\hline CTX-M-14 & 29 & 19 & 4 & 3 & 22 & 35 & 35 & 147 \\
\hline CTX-M-9 & & 1 & & & & & & 1 \\
\hline CTX-M-24 & & 2 & 1 & & 1 & 2 & 1 & 7 \\
\hline CTX-M-27 & 1 & & & & & & & 1 \\
\hline CTX-M-65 & 2 & & & & & 2 & & 4 \\
\hline CTX-M-104 & & & & & & 1 & & 1 \\
\hline CMY-2 & 1 & 3 & 2 & 1 & & & & 7 \\
\hline DHA-1 & 2 & & & & & & & 2 \\
\hline CTX-M-1+9 groups & 1 & 7 & 2 & & 2 & 3 & & 15 \\
\hline CTX-M-14+CTX-M-1 & 1 & & & & & & & 1 \\
\hline CTX-M-14+CTX-M-3 & & 1 & & & & 1 & & 2 \\
\hline CTX-M-14+ CTX-M-55 & & 3 & & & 2 & 1 & & 6 \\
\hline CTX-M-14+ CTX-M-15 & & 3 & 1 & & & 1 & & 5 \\
\hline CTX-M-24+ CTX-M-3 & & & 1 & & & & & 1 \\
\hline CTX-M-14+OXA-10 & 1 & & & & & & & 1 \\
\hline CTX-M-3+ DHA & & & 1 & & & & & 1 \\
\hline CTX-M-14+DHA & 2 & & & & & & & 2 \\
\hline CTX-M-15+CMY-2 & 1 & & & & & & 1 & 2 \\
\hline CTX-M-24+CMY-2 & 0 & & 1 & & & & & 1 \\
\hline Total $^{a}$ & $53(57.0)$ & $43(53.1)$ & $16(43.2)$ & $13(30.2)$ & $38(34.9)$ & $54(49.5)$ & $39(50.0)$ & $256(46.5)$ \\
\hline
\end{tabular}

${ }^{a}$ The number exclude the strains that only encoded $a m p C$ gene.

$b l a_{\mathrm{CTX}-\mathrm{M}-65}$ (4 isolates, $\left.1.6 \%\right)$, bla $a_{\mathrm{CTX}-\mathrm{M}-1}(2$ isolates, including 1 strain co-existed with $\left.b l a_{\mathrm{CTX}-\mathrm{M}-14}\right), b l a_{\mathrm{CTX}-\mathrm{M}-12}$ (1 isolate), $b l a_{\mathrm{CTX}-\mathrm{M}-10}\left(1\right.$ isolate), $b l a_{\mathrm{CTX}-\mathrm{M}-27}$ (1 isolate), $b l a_{\text {CTX-M-104 }}$ (1 isolate), and $b l a_{\text {CTX-M-9 }}$ (1 isolate). Fifteen isolates encoded ESBLs from both CTX-M-1 and CTX-M9 groups (Table 3, Figure 1).

The prevalence of ESBL-producing E. coli strains varied significantly $(p<0.01)$. among the different regions of China, with the highest proportion $(57.0 \%)$ in North China and the lowest proportion (30.2\%) in East China (EC). The prevalence of ESBL-producing isolates significantly differed among different hospitals within South China (SC1-SC5) $(p<0.05)$, the prevalence of ESBLproducing isolates was high in one hospital (SC4; 72.7\%; 8/11 strains) and low in another hospital (SC1; 16.7\%; 6/
36 strains), there was a similar situation within different hospitals in Northwest China (NW1-NW4) $(p<0.05)$. There were no statistical differences in the prevalence of ESBL-producing $E$. coli strains between different hospitals in the remaining five regions.

CTX-M-14 (CTX-M-9 group) was the most common ESBL genotype detected in this study; however, the results suggest that CTX-M-55 (CTX-M-1 group) is also becoming prevalent, with the ratio of the number of CTX-M-55positive isolates to the number of ESBL-positive isolates being 5:8 in SC4, 4:8 in SC5, 6:9 in EC2, and 4:8 in NE1. By contrast, CTX-M-15 was the predominant genotype in EC3 and NW2.

There was no statistical difference $(p=0.6)$ between $E$. coli strains isolated from urinary tract infections $(\mathrm{n}=$ 




Figure 1 National wide distribution of clinical isolates and ESBL-producing E. coli. Geographical location of seven regions from which strains were collected demonstrated in different colour. The two most dominant genotypes in each region were labelled following the prevalence rate of ESBLS.

324, 46.0\% harboured genes for ESBLs), and those isolated from blood ( $\mathrm{n}=44,40.9 \%$ harboured genes for ESBLs).

In total, ten isolates encoded CMY-2 ampC genes and five encoded DHA-1 ampC genes; three of the CMY-2 ampC genes and three DHA-1 ampC genes co-existed with bla $_{\mathrm{CTX}-\mathrm{M}}$.

\section{Characterisation of non-ESBL $\beta$-lactamase genes}

Genes for the broad-spectrum $\beta$-lactamases TEM-1 (347 strains), OXA-1 (35), and SHV-11 (5) were most prevalent among isolates, and were detected either alone or coexisting with other enzymes. One strain contained the gene for the inhibitor-resistant $\beta$-lactamase TEM-30 (and CTX-M-55) and showed no ESBL activity. One strain contained genes for both CTX-M-14 and OXA-10. We believe this is the first reported detection of OXA-10 in $E$. coli in China. The KPC was not detected in this study.

\section{Molecular typing of ESBL-producing $\mathrm{E}$. coli isolates}

MLST revealed 64 different STs, and nine new STs that are not registered in the E. coli MLST database. ST131 was the most abundant type (27 isolates, $12.7 \%$ ), followed by ST69 (14 isolates, $6.6 \%$ ), ST405 (14 isolates, $6.6 \%$ ), and ST38 (12 isolates, $5.6 \%$ ). The sources for the ST131 isolates were distributed across 14 hospitals from seven regions. Among the ST131 isolates, 18 were positive for CTX-M-14, five were positive for CTX-M-55, three were positive for CTX-M-15, and one was positive for both CTX-M-14 and CTX-M-3. Three Northwest hospitals provided $66.7 \%$ of the ST38 strains $(n=12)$. These three hospitals are located far from each other in Xinjiang province. One hospital accounted for 50\% (4/8 isolates) of ESBL-producing strains. ST38 was the dominant type in these three hospitals, but was not found in the one hospital in Xinjiang. A phylogenetic tree of STs detected in this study using a Phylodendron is shown in Figure 2.

\section{Discussion}

The findings of this study reveal, for the first time, the high prevalence of ESBL-producing E. coli associated with community-onset infections in county hospitals across China. The results indicate that $46.5 \%$ of clinical E. coli isolates carried genes for ESBLs, and that this figure varied significantly across the different regions, 


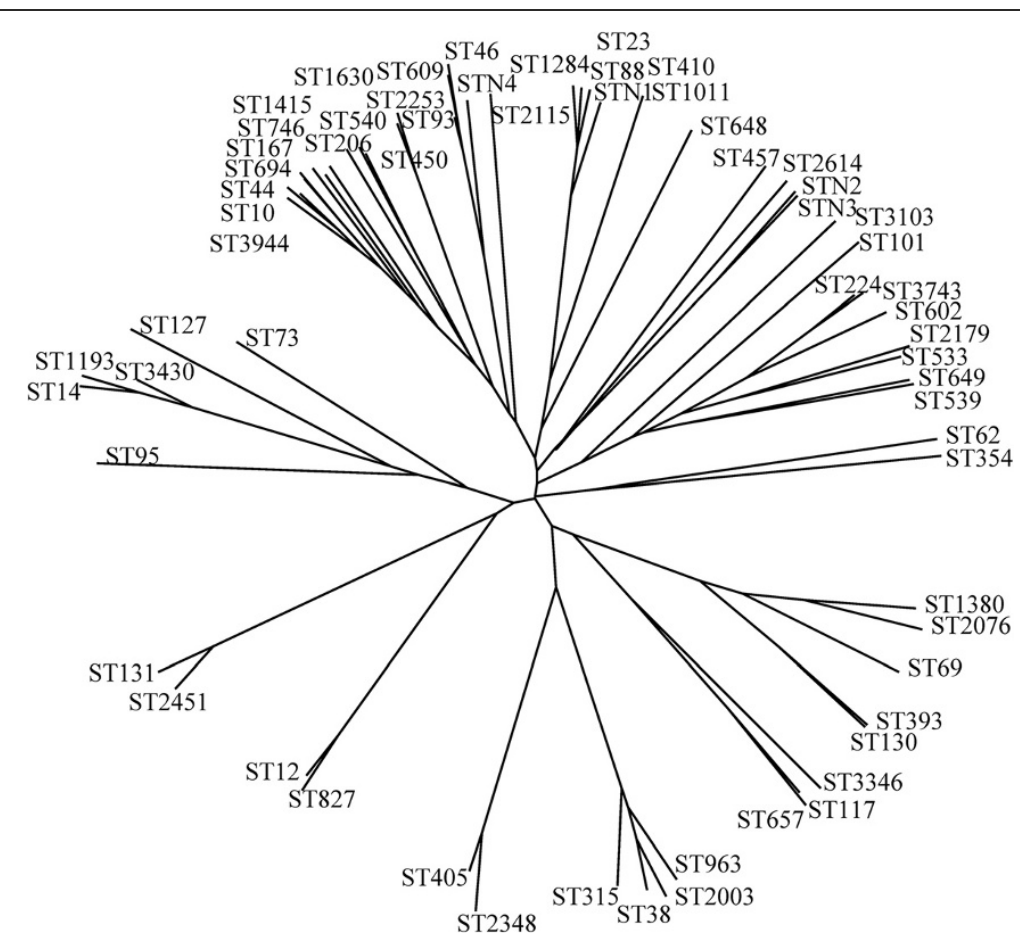

Figure 2 Phylogenetic tree of STs detected in this study using Phylodendron. This tool uses the PHYLIP suite of programs to generate trees from allelic profile data. Phylogenetic tree generated in this study indicated there was no concentrated distribution of STs in ESBL-producing genotypes.

ranging $30.2 \%$ to $57.0 \%$. In particular, the proportion of isolates that carried ESBL genes was $50 \%$ or greater in the North, Northwest, and Southwest regions of China. PCR amplification revealed a high diversity of CTX-Mtype ESBLs in China, with 12 subtypes detected. The results showed that CTX-M-14 was the most abundant of those CTX-M enzymes detected, and that it is prevalent across China. This is supported by previous studies that have reported the prevalence of ESBLs in isolates from both community-associated and hospital-acquired infections in Chinese tertiary hospitals, and also in healthy people from large cities [7,8,32].

A developing characteristic of ESBL epidemiology in several hospitals is the emergence of CTX-M-55 as a dominant genotype. This is the first study to report that the abundance of clinical isolates in China containing CTX-M-55 have exceeded those with CTX-M-15 as the second most common genotype. In 2009, CTX-M-55 was detected in only two of 49 CTX-M-1 group E. coli strains in Guangzhou Province in South China [33]. Following this report, there were limited investigations into the presence of CTX-M-55 in Chinese clinical isolates. However, $\mathrm{Hu}$ et al. recently reported that eight CTX-M55 strains were detected from 17 CTX-M-1 group E. coli isolates from the faeces of healthy humans in Hangzhou (Zhejiang Province) [32].

CTX-M-15 differs from CTX-M-55 by a single amino acid substitution of Ala-77-Val. CTX-M-55 was first detected in clinical isolates of E. coli and K. pneumonia from Thailand in 2005 [34], and was subsequently found in Salmonella spp. in China, the United States, Korea, and Switzerland [35-37]. Although CTX-M-55 is widely distributed in E. coli strains isolated from pets and foodproducing animals, its range currently appears restricted to specific geographic regions, mainly in Asia [15,34,38-41]. Two previous studies of the epidemiology of ESBLproducing $E$. coli strains in food-producing animals in China reported that CTX-M-55 was the second (26.1\%, 29/ $111)$ and third $(18.5 \%, 10 / 54)$ most common genotype, both following CTX-M-14 [39,42]. A further study showed that CTX-M-55 was the second most common $(25 \%, 27 /$ 108 strains) genotype detected among ESBL-producing $E$. coli strains isolated from healthy ducks and environmental samples from a duck farm in South China [40]. These findings suggest that CTX-M-55 has already transferred from animals to humans, and spread among both healthy individuals and patients in China, and that this particular $\beta$ lactamase may be displacing $b l a_{\mathrm{CTX}-\mathrm{M}-14}$ as the most common genotype in some regions.

Drug resistance in $E$. coli can be transferred horizontally between strains that are common to food-producing animals and humans. E. coli can also transfer resistance genes to bacteria that are part of the commensal intestinal flora, and it may serve as an important reservoir for these transmissible traits [43-47]. Winokur et al. reported plasmid transfer of $\beta$-lactamase genes between Salmonella and $E$. 
coli, and suggested that they may have been transmitted between food-producing animals and humans [44]. Fey et al. reported the acquisition of ceftriaxone-resistant Salmonella enterica serotype typhimurium by a 12 -year-old boy from cattle [45]. This finding highlights the potential threat to public health through the transfer of highly resistant bacterial strains from livestock to humans, particularly farmers, ranchers, and animal handlers [45]. Findings from this study, and others, suggest that CTX-M-55 can be transmitted from animals to humans. Most outpatients in county hospitals live in rural areas and are likely to have contact with infected food-producing animals and farm sewage. Further investigations are needed to test this hypothesis and resolve the mechanism by which blaCTX-M55 transfers to, and exists in, humans.

In this study, 64 different STs (including nine new STs) were detected among 213 ESBL-producing E. coli isolates, and ST131 was the most abundant type (12.7\%). These findings are similar to those from a tertiary hospital investigation, which reported that $9.6 \%$ of $94 b l a_{\mathrm{CTX}-\mathrm{M}-14^{-}}$and

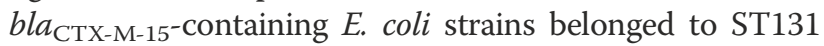
[48]. An investigation of ESBL-producing E. coli isolated from river samples and the faeces of healthy humans found that $14.4 \%(20 / 139)$ of isolates belonged to ST131 [32]. The findings indicate that no particular ST of E. coli is predominant in China, unlike European and North American countries where there is a higher prevalence of ST131 [6]. For example, 53\% of ESBL-producing E. coli isolates belonged to ST131 in the United States [5]. A study from Calgary for the period 2000-2007 revealed that E. coli clone ST131, which produces CTX-M-15, was an important cause of community-onset bacteraemia, with its incidence increasing from $6 \%(1 / 18)$ in $2000-2003$ to $41 \%$ (20/49) in 2004-2007 [49]. In one region of the United Kingdom, $64 \%$ of community-acquired cefpodoximeresistant $E$. coli infections were caused by ST131 [50]. Similarly, data from Belgium covering the period 20062007 shows that $62 \%$ of CTX-M-15-carrying E. coli causing community-acquired infections belonged to ST131. [51] In France, 25\% of community-onset ESBL-producing E. coli infections belonged to ST131 [13].

No dominant ST type was detected in any region; however, in Northwest China, 19.5\% (8/41) of isolates belonged to ST38 (detected in three of four hospitals). These four hospitals are all located in Xinjiang province, and are far away from each other. Results indicated that



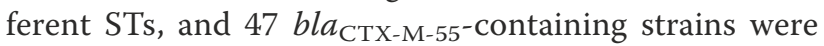
scattered between 22 different STs. There was no concentrated distribution of STs in these two, or any other, ESBL-producing genotypes (Figure 2). The results indicate no evolutionary convergent relationships among ESBL-producing E. coli in Chinese hospitals, and suggest that the clonal dissemination of ESBL-producing strains is complicated in China and requires further investigation.

This study provides the first report of an OXA-10-like $\beta$-lactamase sequence detected in a member of the Enterobacteriaceae in China, although it was previously reported in Pseudomonas aeruginosa [52]. OXA-10 has also been recorded in multi-drug-resistant clinical isolates of $E$. coli, K. pneumonia, and Proteus. mirabilis [53-55]. OXA10 is a class D broad-spectrum $\beta$-lactamase that hydrolyses oxacillin, methicillin, and cloxacillin, and is inhibited by sodium chloride and clavulanic acid [56]. This $\beta$ lactamase was first detected in P. aeruginosa in 1988 [56], and has a similar function to OXA-2 as the parent of OXA-type ESBL, the extended-spectrum variant was continually found in $P$. aeruginosa during the past two decades, although it has not been detected in Enterobacteriaceae $[57,58]$. The detection of OXA-10 in the Enterobacteriaceae reported here, and in other studies, suggests further investigations are needed into the origin of this $P$. aeruginosa-derived $\beta$-lactamase and its transmission.

\section{Conclusions}

In summary, this study reports high rates of ESBLproducing isolates of $E$. coli community-associated infections in county hospitals in China; although the prevalence was lower than in tertiary hospitals. The CTX-M ESBL was the dominant enzyme, and CTX-M-14 was the major molecular type detected in community-onset infections. A diverse range of STs was detected, and no evolutionary convergent relationship among ESBL-producing E. coli was found. We also report the detection of the OXA-10 type of ESBL in clinical isolates of E. coli. These evolutionary characteristics of ESBL epidemiology in clinical strains of $E$. coli may complicate the future management of antibiotic resistance in China if no effective measures are taken. Further investigations are needed to resolve the mechanisms underlying the increasing incidences of CTX-M-55 and the emergence of OXA-10 in strains of $E$. coli in county hospitals.

\section{Additional file}

Additional file 1: List of the participant hospitals. The list and the geographic of 30 county hospitals in this study.

\section{Competing interests}

The authors declare that they have no competing interests.

\section{Authors' contributions}

$J Z, B Z, L Z, L L$ and $Y X$ designed the study, JZ, LZ, ZW and JJ performed the experiments, JZ, BZ, YX analyzed the data, JZ analyzed sequences, JZ, BZ, LL and $Y X$ wrote the manuscript which was corrected and approved by all the other co-authors. All authors read and approved the final manuscript.

\section{Acknowledgements}

The authors are grateful to all the participants for their help during collection of the isolates for this project. This work was supported by the Research 
Special Fund for Public Welfare Industry of Health, Ministry of Health of China (201002021), the National Natural Science Foundation of China (Grant No. 81361138021 and 81301461) and Zhejiang Provincial Natural Science Foundation of China (LQ13H190002).

Received: 20 May 2014 Accepted: 24 November 2014 Published online: 03 December 2014

\section{References}

1. Bradford PA: Extended-spectrum beta-lactamases in the 21st century: characterization, epidemiology, and detection of this important resistance threat. Clin Microbiol Rev 2001, 14(4):933-951. table of contents.

2. Bush K, Jacoby GA, Medeiros AA: A functional classification scheme for beta-lactamases and its correlation with molecular structure. Antimicrob Agents Chemother 1995, 39(6):1211.

3. Mutter GL, Baak JP, Fitzgerald JT, Gray R, Neuberg D, Kust GA, Gentleman R, Gullans SR, Wei LJ, Wilcox M: Global expression changes of constitutive and hormonally regulated genes during endometrial neoplastic transformation. Gynecol Oncol 2001, 83(2):177-185.

4. Livermore DM, Canton R, Gniadkowski M, Nordmann P, Rossolini GM, Arlet G, Ayala J, Coque TM, Kern-Zdanowicz I, Luzzaro F, Poire L, Woodford N: CTX-M: changing the face of ESBLs in Europe. J Antimicrob Chemother 2007, 59(2):165-174

5. Doi Y, Park YS, Rivera JI, Adams-Haduch JM, Hingwe A, Sordillo EM, Lewis JS 2nd, Howard WJ, Johnson LE, Polsky B, Jorgensen JH, Richter SS, Shutt KA, Paterson DL: Community-associated extended-spectrum beta-lactamaseproducing Escherichia coli infection in the United States. Clin Infect Dis 2013, 56(5):641-648

6. Rogers BA, Sidjabat HE, Paterson DL: Escherichia coli O25b-ST131: a pandemic, multiresistant, community-associated strain. J Antimicrob Chemother 2011, 66(1):1-14.

7. Yu Y, Ji S, Chen Y, Zhou W, Wei Z, Li L, Ma Y: Resistance of strains producing extended-spectrum beta-lactamases and genotype distribution in China. J Infect 2007, 54(1):53-57.

8. da Silva Dias RC, Borges-Neto AA, D'Almeida Ferraiuoli Gl, de-Oliveira MP, Riley LW, Moreira BM: Prevalence of AmpC and other beta-lactamases in enterobacteria at a large urban university hospital in Brazil. Diagn Microbiol Infect Dis 2008, 60(1):79-87.

9. Munday C, Xiong J, Li C, Shen D, Hawkey P: Dissemination of CTX-M type $\beta$-lactamases in Enterobacteriaceae isolates in the People's Republic of China. Int J Antimicrob Agents 2004, 23(2):175-180.

10. Baurin $S$, Vercheval $L$, Bouillenne F, Falzone $C$, Brans $A$, Jacquamet $L$, Ferrer U, Sauvage E, Dehareng D, Frere JM, Charlier P, Galleni M, Kerff F: Critical role of tryptophan 154 for the activity and stability of class D beta-lactamases. Biochemistry 2009, 48(47):11252-11263.

11. Baas PW, Ahmad FJ: Force generation by cytoskeletal motor proteins as a regulator of axonal elongation and retraction. Trends Cell Biol 2001, 11(6):244-249.

12. Lartigue MF, Zinsius C, Wenger A, Bille J, Poirel L, Nordmann P: Extendedspectrum beta-lactamases of the CTX-M type now in Switzerland. Antimicrob Agents Chemother 2007, 51(8):2855-2860.

13. Arpin C, Quentin C, Grobost F, Cambau E, Robert J, Dubois V Coulange L, Andre C: Scientific committee of O: nationwide survey of extendedspectrum \{beta\}-lactamase-producing Enterobacteriaceae in the French community setting. J Antimicrob Chemother 2009, 63(6):1205-1214.

14. Khanna N, Boyes J, Lansdell PM, Hamouda A, Amyes SG: Molecular epidemiology and antimicrobial resistance pattern of extendedspectrum-beta-lactamase-producing Enterobacteriaceae in Glasgow, Scotland. J Antimicrob Chemother 2012, 67(3):573-577.

15. Livermore DM, Hawkey PM: CTX-M: changing the face of ESBLs in the UK. J Antimicrob Chemother 2005, 56(3):451-454.

16. Rawat $V$, Singhai $M$, Verma PK: Detection of different beta-Lactamases and their co-existence by using various discs combination methods in clinical isolates of enterobacteriaceae and pseudomonas spp. J Lab Phys 2013 5(1):21-25.

17. Bell JM, Turnidge JD, Gales AC, Pfaller MA, Jones RN, Sentry ASG: Prevalence of extended spectrum beta-lactamase (ESBL)-producing clinical isolates in the Asia-Pacific region and South Africa: regional results from SENTRY Antimicrobial Surveillance Program (1998-99). Diagn Microbiol Infect Dis 2002, 42(3):193-198.
18. Heffernan HM, Woodhouse RE, Pope CE, Blackmore TK: Prevalence and types of extended-spectrum beta-lactamases among urinary Escherichia coli and Klebsiella spp. in New Zealand. Int J Antimicrob Agents 2009, 34(6):544-549.

19. Liu W, Chen L, Li H, Duan H, Zhang Y, Liang X, Li X, Zou M, Xu L, Hawkey PM: Novel CTX-M \{beta\}-lactamase genotype distribution and spread into multiple species of Enterobacteriaceae in Changsha, Southern China. J Antimicrob Chemother 2009, 63(5):895-900.

20. Yang $Q$, Zhang $H$, Wang $Y, X u Y$, Chen M, Badal RE, Wang H, Ni Y, Yu Y, Hu B, Sun Z, Huang W, Wang Y, Wu A, Feng $X$, Liao K, Shen D, Hu Z, Chu Y, Lu J, Cao B, Su J, Gui B, Duan Q, Zhang S, Shao H, Kong H, Hu Y, Ye H: A 10 year surveillance for antimicrobial susceptibility of Escherichia coli and Klebsiella pneumoniae in community- and hospital-associated intra-abdominal infections in China. J Med Microbiol 2013, 62(Pt 9):1343-1349.

21. Xiao YH, Giske CG, Wei ZQ, Shen P, Heddini A, Li LJ: Epidemiology and characteristics of antimicrobial resistance in China. Drug Resist Updat 2011, 14(4-5):236-250

22. Xiao Y, Zhang J, Zheng B, Zhao L, Li S, Li L: Changes in Chinese policies to promote the rational use of antibiotics. PLOS Med 2013, 10(11):e1001556.

23. Xiao Y, Shen P, Wei Z, Chen Y, Kong H, Yang Q, Zhang W, Chen X, Li L: National surveillance of antimicrobial resistance of Mohnarin. Chin $J$ Nosocomiology 2012, 22(22):4946-4952.

24. Jiang S, Zheng B, Ding W, Lv L, Ji J, Zhang H, Xiao Y, Li L: Whole-genome sequence of Staphylococcus hominis, an opportunistic pathogen. J Bacteriol 2012, 194(17):4761-4762.

25. Clinical and Laboratory Standards Institute: Performance Standards for Antimicrobial Susceptibility Testing. 21th Informational Supplement, Document M100-S21s. Wayne, PA, USA: CLSI; 2011.

26. Holmes DS, Quigley M: A rapid boiling method for the preparation of bacterial plasmids. Anal Biochem 1981, 114(1):193-197.

27. Dallenne C, Da Costa A, Decre D, Favier C, Arlet G: Development of a set of multiplex PCR assays for the detection of genes encoding important beta-lactamases in Enterobacteriaceae. J Antimicrob Chemother 2010, 65(3):490-495

28. Zhang W, Luo Y, Li J, Lin L, Ma Y, Hu C, Jin S, Ran L, Cui S: Wide dissemination of multidrug-resistant Shigella isolates in China. J Antimicrob Chemother 2011, 66(11):2527-2535.

29. Sun Y, Zeng Z, Chen S, Ma J, He L, Liu Y, Deng Y, Lei T, Zhao J, Liu JH: High prevalence of bla(CTX-M) extended-spectrum beta-lactamase genes in Escherichia coli isolates from pets and emergence of CTX-M-64 in China. Clin Microbiol Infect 2010, 16(9):1475-1481.

30. Zhang KJ, Han X, Hong XY: Various infection status and molecular evidence for horizontal transmission and recombination of Wolbachia and Cardinium among rice planthoppers and related species. Insect Sci 2013, 20(3):329-344.

31. Wirth T, Falush D, Lan R, Colles F, Mensa P, Wieler LH, Karch H, Reeves PR, Maiden MC, Ochman H, Achtman M: Sex and virulence in Escherichia coli: an evolutionary perspective. Mol Microbiol 2006, 60(5):1136-1151.

32. Hu YY, Cai JC, Zhou HW, Chi D, Zhang XF, Chen WL, Zhang R, Chen GX: Molecular typing of CTX-M-producing escherichia coli isolates from environmental water, swine feces, specimens from healthy humans, and human patients. App/ Environ Microbiol 2013, 79(19):5988-5996.

33. Zhuo C, Su D, Li H, Wang L, Liao K, Wang M, Zhi Z, Guo Z, Wei Y, Geng H: Study on CIX-M type ESBLs-producing Escherichia coli and Klebsiella pneumoiae in Guangzhou. Chin J Lab Med 2009, 32(10):1114-1119.

34. Kiratisin P, Apisarnthanarak A, Saifon P, Laesripa C, Kitphati R, Mundy LM: The emergence of a novel ceftazidime-resistant CTX-M extendedspectrum beta-lactamase, CTX-M-55, in both community-onset and hospital-acquired infections in Thailand. Diagn Microbiol Infect Dis 2007, 58(3):349-355

35. Shi W-F, Zhou J, Qin J-P: Transconjugation and genotyping of the plasmid-mediated AmpC beta-lactamase and extended-spectrum beta-lactamase genes in Klebsiella pneumoniae. Chin Med J (Engl) 2009, 122(9):1092-1096.

36. Sjolund-Karlsson M, Howie R, Krueger A, Rickert R, Pecic G, Lupoli K, Folster JP, Whichard JM: CTX-M-producing non-Typhi Salmonella spp. isolated from humans, United States. Emerg Infect Dis 2011, 17(1):97-99.

37. Dahmen S, Madec JY, Haenni M: F2:A-:B- plasmid carrying the extendedspectrum beta-lactamase bla(CTX-M-55/57) gene in Proteus mirabilis isolated from a primate. Int J Antimicrob Agents 2013, 41(6):594-595.

38. Dinubile MJ, Friedland I, Chan CY, Motyl MR, Giezek H, Shivaprakash M, Weinstein RA, Quinn JP: Bowel colonization with resistant gram-negative 
bacilli after antimicrobial therapy of intra-abdominal infections: observations from two randomized comparative clinical trials of ertapenem therapy. Eur $J$ Clin Microbiol Infect Dis 2005, 24(7):443-449.

39. Zheng H, Zeng Z, Chen S, Liu Y, Yao Q, Deng Y, Chen X, Lv L, Zhuo C, Chen Z, Liu J: Prevalence and characterisation of CTX-M beta-lactamases amongst Escherichia coli isolates from healthy food animals in China. Int J Antimicrob Agents 2012, 39(4):305-310.

40. Ma J, Liu JH, Lv L, Zong Z, Sun Y, Zheng H, Chen Z, Zeng ZL: Characterization of extended-spectrum beta-lactamase genes found among Escherichia coli isolates from duck and environmental samples obtained on a duck farm. Appl Environ Microbiol 2012, 78(10):3668-3673.

41. Zurfluh K, Hachler H, Nuesch-Inderbinen M, Stephan R: Characteristics of extended-spectrum beta-lactamase- and carbapenemase-producing Enterobacteriaceae Isolates from rivers and lakes in Switzerland. Appl Environ Microbiol 2013, 79(9):3021-3026

42. Li J, Ma Y, Hu C, Jin S, Zhang Q, Ding H, Ran L, Cui S: Dissemination of cefotaxime-M-producing Escherichia coli isolates in poultry farms, but not swine farms, in China. Foodborne Pathog Dis 2010, 7(11):1387-1392.

43. Seiffert SN, Hilty M, Perreten $V$, Endimiani A: Extended-spectrum cephalosporin-resistant gram-negative organisms in livestock: an emerging problem for human health? Drug Resist Updat 2013, 16(1-2):22-45.

44. Winokur P, Vonstein D, Hoffman L, Uhlenhopp E, Doern G: Evidence for Transfer of CMY-2 AmpC $\beta$-Lactamase Plasmids between Escherichia coli andSalmonella Isolates from Food Animals and Humans. Antimicrob Agents Chemother 2001, 45(10):2716-2722.

45. Fey PD, Safranek TJ, Rupp ME, Dunne EF, Ribot E, Iwen PC, Bradford PA, Angulo FJ, Hinrichs SH: Ceftriaxone-resistant Salmonella infection acquired by a child from cattle. N Engl J Med 2000, 342(17):1242-1249.

46. Angulo FJ, Mølbak K: Human health consequences of antimicrobial drug -resistant salmonella and other foodborne pathogens. Clin Infect Dis 2005, 41(11):1613-1620.

47. Li XZ, Mehrotra M, Ghimire S, Adewoye L: beta-Lactam resistance and beta-lactamases in bacteria of animal origin. Vet Microbiol 2007, 121(3-4):197-214.

48. Cao X, Cavaco LM, Lv Y, Li Y, Zheng B, Wang P, Hasman H, Liu Y, Aarestrup FM: Molecular characterization and antimicrobial susceptibility testing of Escherichia coli isolates from patients with urinary tract infections in 20 Chinese hospitals. J Clin Microbiol 2011, 49(7):2496-2501.

49. Pitout JD, Gregson DB, Campbell L, Laupland KB: Molecular characteristics of extended-spectrum- $\beta$-lactamase-producing Escherichia coli isolates causing bacteremia in the Calgary Health Region from 2000 to 2007: emergence of clone ST131 as a cause of community-acquired infections. Antimicrob Agents Chemother 2009, 53(7):2846-2851.

50. Lau SH, Kaufmann ME, Livermore DM, Woodford N, Willshaw GA, Cheasty T, Stamper K, Reddy S, Cheesbrough J, Bolton FJ: UK epidemic Escherichia coli strains A-E, with CTX-M-15 $\beta$-lactamase, all belong to the international O25: H4-ST131 clone. J Antimicrob Chemother 2008 62(6):1241-1244

51. Smet A, Martel A, Persoons D, Dewulf J, Heyndrickx M, Claeys G, Lontie M, Van Meensel B, Herman L, Haesebrouck F: Characterization of extended-spectrum $\beta$-lactamases produced by Escherichia coli isolated from hospitalized and nonhospitalized patients: emergence of CTX-M-15-producing strains causing urinary tract infections. Microb Drug Resist 2010, 16(2):129-134.

52. Wu Y, Li H, Li J, Huang ZH: Detection of Pseudomonas aeruginosa carried a new array of gene cassettes within class 1 integron isolated from a teaching hospital in Nanjing, China. J Microbiol 2008, 46(6):687-691.

53. Girlich D, Poirel L, Leelaporn A, Karim A, Tribuddharat C, Fennewald M, Nordmann P: Molecular epidemiology of the integron-located VEB-1 extended-spectrum beta-lactamase in nosocomial enterobacterial isolates in Bangkok, Thailand. J Clin Microbiol 2001, 39(1):175-182.

54. Kiratisin P, Apisarnthanarak A, Laesripa C, Saifon P: Molecular characterization and epidemiology of extended-spectrum-beta-lactamase-producing Escherichia coli and Klebsiella pneumoniae isolates causing health care-associated infection in Thailand, where the CTX-M family is endemic. Antimicrob Agents Chemother 2008, 52(8):2818-2824.

55. Poirel L, Schrenzel J, Cherkaoui A, Bernabeu S, Renzi G, Nordmann P: Molecular analysis of NDM-1-producing enterobacterial isolates from Geneva, Switzerland. J Antimicrob Chemother 2011, 66(8):1730-1733.
56. Huovinen P, Huovinen S, Jacoby G: Sequence of PSE-2 beta-lactamase. Antimicrob Agents Chemother 1988, 32(1):134-136.

57. Couture F, Lachapelle J, Levesque RC: Phylogeny of LCR-1 and OXA-5 with class A and class D beta-lactamases. Mol Microbiol 1992, 6(12):1693-1705.

58. Poirel L, Naas T, Nordmann P: Class D ss-lactamases: diversity, epidemiology and genetics. Antimicrob Agents Chemother 2010, 54(1):24-38.

doi:10.1186/s12879-014-0659-0

Cite this article as: Zhang et al:: Nationwide high prevalence of CTX-M and an increase of CTX-M-55 in Escherichia coli isolated from patients with community-onset infections in Chinese county hospitals.

BMC Infectious Diseases 2014 14:659.

\section{Submit your next manuscript to BioMed Central and take full advantage of:}

- Convenient online submission

- Thorough peer review

- No space constraints or color figure charges

- Immediate publication on acceptance

- Inclusion in PubMed, CAS, Scopus and Google Scholar

- Research which is freely available for redistribution 